\title{
Antropometric Measurements in Different Ethnic groups of Nepalese New Borns
}

\author{
Malla K' , Mall T², Rao S3, Gauchan E , Basnet $S^{5}$, Koirala DP6 \\ ${ }^{1}$ Dr. Kalpana K Malla, MBBS, MD, Associate Professor, ${ }^{2}$ Dr. Tejesh Malla, MBBS, MD, Associate Professor, ${ }^{3}$ Sheshagiri Rao, \\ MBBS, MD, Professor, ${ }^{4}$ Dr. Eva Gauchan, MBBS, MD, Lecturer, ${ }^{5}$ Dr. Sahisnuta Basnet, MBBS, MD, Lecturer, ${ }^{6}$ Dr. Deepak Prasad \\ Koirala, MBBS, MD, Lecturer. All from the Department of Paediatrics, Manipal College of Medical Science, Pokhara, Nepal.
}

Address for correspondence: Dr. Kalpana Malla, E-mail: kalpana_malla@hotmail.com

\begin{abstract}
Introduction: There is a wide variation in normal birth weight, length and head circumference of newborns. The standards formulated by Western workers may not be very reliable to this part of world because of wide variations in normal range of length, weight and head circumference in different ethnic groups. This study aims to determine the anthropometric values - birth weight, length and head circumference in Term and Preterm newborns of different ethnic groups in this region of the country and to see if this can be used as a standard for taking the anthropometric measurements. Materials and Methods: A prospective study of 600 newborns born in Manipal Teaching Hospital, Pokhara from July 2009-June 2010. A detailed anthropometric measurement (weight, length, and head circumference) of all newborns was taken on $3^{\text {rd }}$ day of life. Results: Six major Ethnic groups were noted Brahmin, Gurung, Dalit, Chettri, Magar and Newar. There were $54 \%$ males and $46 \%$ females among which $18.16 \%$ were preterms, $20.66 \%$ small for gestation age, $81.50 \%$ term and $0.33 \%$ posterm. The mean weight, length and head circumference of term babies were $2.817 \pm 0.61 \mathrm{gms}, 47.68 \pm 2.48 \mathrm{~cm}, 33.56 \pm 2.02 \mathrm{~cm}$ and for preterm babies it was $2.215 \pm$ $0.41 \mathrm{gms}, 46.36 \pm 2.39 \mathrm{~cm}, 32.23 \pm 2.03 \mathrm{~cm}$ respectively. There were $25 \%$ low birth weight ( $\mathrm{n}=151$, highest number in Brahmins-27\%), $74.16 \%$ normal weight $(n=445)$ and $0.66 \%$ over weight $(n=4$, all were gurungs) babies. In Term newborns weight, length and head circumference was noted to be highest in Gurungs $(3.3004 \mathrm{gms}, 49.35 \mathrm{~cm}, 34.72 \mathrm{~cm})$ and was statistically significant $(\mathrm{p}<0.000)$. Weight and length of Brahmins was lowest $(2.578 \mathrm{gms}, 45.49 \mathrm{~cm})$ and head circumference was lowest in Dalits $(30.88 \mathrm{~cm}$, statistically significant $<0.000)$. In case of preterms highest weight and length was seen in Magars (2.387gms, $47.90 \mathrm{~cm})$ but head circumference was highest in Gurungs $(34.18 \mathrm{~cm})$ whereas weight was lowest in chettri $(2.1609 \mathrm{gms})$, length in Brahmin $(44.61 \mathrm{~cm})$ and OFC in Dalits $(29.92 \mathrm{~cm})$. These parameters were directly proportion with gestation age and was statistically significant $(p<0.000)$. Conclusion: The present study highlights the mean weight, length and head circumference of term and preterm newborns in different ethnic groups and gestation age. These parameters were directly proportion to gestation age but were variable in different Ethnic groups. Therefore a study in larger population could give us a different standard for anthropometric measurements in Nepalese newborns.
\end{abstract}

Key words: Anthropometry Measurements, N.ewborn, Nepal

\section{Introduction}

$\mathrm{T}$ here is a wide variation in normal birth weight, length and head circumference of newborns. Different standards of norms are used in different parts of the world. Therefore the standards formulated by Western workers may not be very reliable to this part of world because of wide variations in normal range of length, weight and head circumference in different ethnic groups. This study aims to determine the anthropometric values birth weight, length and head circumference in Term and Preterm newborns of different ethnic groups in this region of the country and to see if this can be used as a standard for taking the anthropometric measurements.

\section{Materials and Methods}

This is prospective observational study which was undertaken over a period of 1 year from July 2009 to June 2010. Cases were enrolled from postnatal ward, these included babies delivered in Manipal Teaching Hospital, Pokhara (A tertiary care hospital of western region of the 
country). Consent was taken from mothers after they were explained about the measurements. A total of 2000 healthy term and preterm neonates were subjected to clinical examination. Gestational age was assessed according to the first day of last menstrual period and was cross checked by Ballard scoring'. Anthropometric parameters that included; weight, length and occipito frontal circumference (OFC) were recorded on day 3 of life so that the error due to skull molding and caput succedaneum for the head circumference and excess body fluid loss in the initial days for weight loss could be eliminated. Common ethnic groups noted were Brahmins, Gurungs, Chettris, Dalits, Magars and Newars. Out of these 2000 babies 100 consequitive babies from each of the above mentioned ethnic groups $(n=600)$ were selected for the study. The remaining 1400 babies were excluded from the study. Normal and caeserian delivered babies of any sex, gestation age $>32$ weeks and those from a high socioeconomic background (family income $>5000$ Rupees per month) were also included in the study. Exclusion criteria consisted of babies with congenital anomalies, chromosomal anomalies, babies measured 3 days before or after birth, gestational age $\leq$ 32 weeks, birth weight $\leq 1500 \mathrm{gms}$, preterm babies with complications, ill babies and maternal illness during antenatal period. Detail anthropometric measurements were taken by the same persons to minimize subjective error. Same weighing scale and same measuring tape were used to take the weight and head circumference respectively. Infantometer was used to take the length. Data collected was tabulated and analyzed using statistical package SPSS 19.0 version. Microsoft Excel (2003) and SPSS were used for plotting figures. Two tailed t-test was used to compare the anthropometric parameters (birth weight, length, head circumference) of different ethnic groups.

\section{Results}

There were $326 / 600$ (54\%) males and 274/600 (46\%) females (Figure 1). Classification of newborns in relation to gestation age showed that small for gestation age (SGA) babies (20.66\%) were more than the preterm babies (18.16\%, Table 1). There were $77.16 \%$ appropriate for age (AGA) and $2.16 \%$ large for gestation age (LGA) babies. Highest number of both SGA (27.41\%) and Preterms (33.02\%) were observed in the Brahmin population (Figure 2). Preterms were higher in Brahmin, Newar and Magar and SGA was higher in Dalit, Gurung and Chettri populations (Figure 2). 9/13 LGA was noted in Gurungs (Figure 2 and Table 1). The Mean \pm SD for weight, length and OFC for term babies were $2.8177 \pm 0.61 \mathrm{gms}$, $47.68 \pm 2.48 \mathrm{~cm}, 33.56 \pm 2.02 \mathrm{~cm}$ respectively and for preterm babies it was $2.2153 \pm 0.41 \mathrm{gms}, 46.36 \pm 2.39 \mathrm{~cm}$, $32.23 \pm 2.03 \mathrm{~cm}$ respectively (Table 2). Table 2 also shows these parameters in different Ethnic groups where the mean $\pm S D$ for weight, length, OFC for Brahmin was $2.5788 \pm 0.59 \mathrm{gms}$ (Term), 2.2016 $\pm 0.49 \mathrm{gms}$ (preterm); $\quad 45.49 \pm 3.48 \mathrm{~cm} \quad$ (term) $44.61 \pm 3.22 \mathrm{~cm}$ (Preterm); $33.41 \pm 2.29 \mathrm{~cm} \quad$ (Term) $33.02 \pm 2.16 \mathrm{~cm}$ (Preterm) respectively. Similarly for Gurung this was $3.3004 \pm 0.58 \mathrm{gms} \quad$ (Term) $2.1166 \pm 0.48 \mathrm{gms}$ (preterm); $49.35 \pm 1.41 \mathrm{~cm} \quad$ (Term), $47.83 \pm 1.38 \mathrm{~cm}$ (Preterm); $34.72 \pm 0.81 \mathrm{~cm}$ (Term), $34.18 \pm 0.78 \mathrm{~cm}$ (Preterm); Dalit 2.6079 $\pm 0.43 \mathrm{gm}$ (Term), 2.2153 $\pm 0.41 \mathrm{gms}$ (Preterm); $46.49 \pm 2.22 \mathrm{~cm}$ (Term), $45.07 \pm 2.16 \mathrm{~cm}$ (Preterm); 30.88 $\pm 1.96 \mathrm{~cm}$ (Term)， $29.92 \pm 1.87 \mathrm{~cm}$ (Preterm); Chettri 2.7305 $\pm 0.52 \mathrm{gms}$ (Term) 2.1609 $\pm 0.38 \mathrm{gms}$ (Preterm; $47.93 \pm 1.84 \mathrm{~cm} \quad$ (Term), $47.45 \mathrm{~cm} \pm 1.81 \quad$ (Preterm; $34.08 \pm 1.10 \mathrm{~cm}$ (Term), $33.81 \pm 0.98 \mathrm{~cm}$ (Preterm); Magar $2.8870 \pm 0.6 \mathrm{gms}$ (Term), 2.3875 $\pm 0.87 \mathrm{gms}$ (Preterm), $48.49 \pm 1.61 \mathrm{~cm} \quad$ (Term), $47.90 \pm 1.56 \mathrm{~cm} \quad$ (Preterm); $33.79 \pm 1.52 \mathrm{~cm}$ (Term), $33.55 \pm 1.46 \mathrm{~cm}$ (Preterm); Newar $2.8000 \pm 0.56 \mathrm{gms}$ (Term), 2.3260 $\pm 0.48 \mathrm{gms}$ (Preterm); $48.33 \pm 1.37 \mathrm{~cm}$ (Term) $47.69 \pm 1.28 \mathrm{~cm}$ (Preterm); $34.51 \pm 1$. (Term) $34.09 \pm 1.27 \mathrm{~cm}$ (Preterm) respectively. Figure 3 shows weight and Figure 4 shows OFC in different ethnic groups where it is observed that highest number of Low birth babies (LBW) was found in Brahmins (27.15\%) followed by Magar (19.86\%), Newar (17.21\%), Dalit (14.56 \%), Chettri (13.90\%). Only 7.28\% LBW was seen in Gurung population (Figure 3). OFC was $<33 \mathrm{~cm}$ in maximum babies (80\%) in Dalits, which was statistically significant (Table 3). Correlation of weight, length and OFC with gestation age was also seen (Table 4) and these parameters were directly proportion to gestation age and was statistically significant $(p<0.000)$.

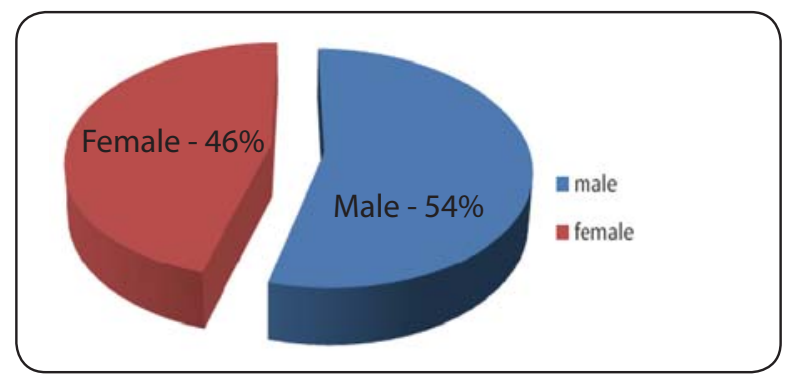

Fig 1: Distribution of sex of babies 


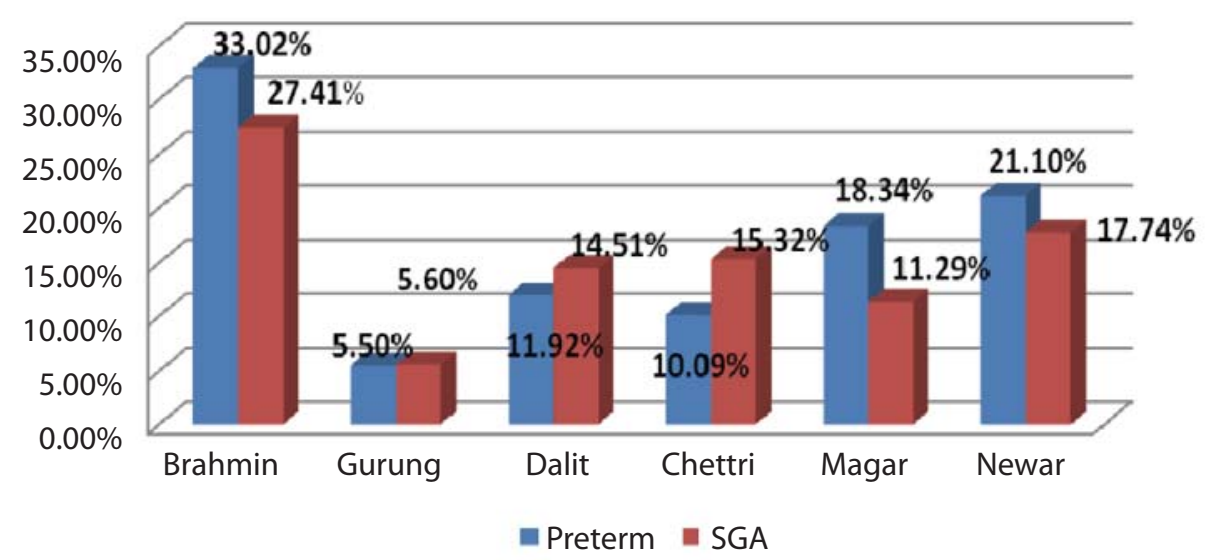

Fig 2: Distribution of preterm and SGA babies in different Ethnic Groups

Table 1: Mean birth weight for gestational age in six ethnic groups.

\begin{tabular}{|c|c|c|c|c|}
\hline Gestation age & SGA & AGA & LGA & Total \\
\hline Brahmin : Preterm & 19 & 17 & 0 & 36 \\
\hline Term & 15 & 49 & 0 & 64 \\
\hline Posterm & 0 & 0 & 0 & 0 \\
\hline Gurung: Preterm & 3 & 3 & 0 & 6 \\
\hline Term & 4 & 81 & 9 & 94 \\
\hline Posterm & 0 & 0 & 0 & 0 \\
\hline Dalit : Preterm & 6 & 7 & 0 & 13 \\
\hline Term & 12 & 75 & 0 & 87 \\
\hline Posterm & 0 & 0 & 0 & 0 \\
\hline Chettri: Preterm & 9 & 2 & 0 & 11 \\
\hline Term & 10 & 75 & 2 & 87 \\
\hline Posterm & 0 & 2 & 0 & 2 \\
\hline Magar: Preterm & 10 & 10 & 0 & 20 \\
\hline Term & 14 & 64 & 2 & 80 \\
\hline Posterm & 0 & 0 & 0 & 0 \\
\hline Newar: Preterm & 13 & 10 & 0 & 23 \\
\hline Term & 9 & 68 & 0 & 77 \\
\hline Posterm & 0 & 0 & 0 & 0 \\
\hline Total & $124(20.66 \%)$ & 463 (77.16\%) & $13(2.16 \%)$ & 600 \\
\hline
\end{tabular}

*Preterm (<37 weeks) n=109 (18.16\%), **Term (37-42 weeks) $n=489(81.50 \%),{ }^{* * * P o s t e r m ~(>42 ~ w e e k s) ~} n=2(0.33 \%),{ }^{* * *}$ Small for gestation age $n=124(20.66 \%)$

Table 2: Mean \pm SD of weight, length and OFC of babies in different ethnic groups

\begin{tabular}{|l|c|c|c|}
\hline Ethnic group of babies & Mean Weight \pm SD & Mean Length \pm SD & Mean OFC \pm SD \\
\hline Brahmin: & $2.5788 \pm 0.59632$ & $45.4900 \pm 3.48299$ & $33.4100 \pm 2.29666$ \\
& $2.2016 \pm 0.49012$ & $44.6109 \pm 3.22456$ & $33.027 \pm 2.16751$ \\
\hline Term & $3.3004 \pm 0.58373$ & $49.3500 \pm 1.41689$ & $34.7200 \pm 0.81749$ \\
\hline Gurung: & $2.2166 \pm 0.48465$ & $47.8331 \pm 1.38796$ & $34.1830 \pm 0.78910$ \\
\hline Term & $2.6097 \pm 0.43009$ & $46.4900 \pm 2.22699$ & $30.8800 \pm 1.96062$ \\
Preterm & $2.2153 \pm 0.41981$ & $45.0760 \pm 2.16589$ & $29.9230 \pm 1.87675$ \\
\hline Dalit: & \multicolumn{3}{|l}{} \\
\hline Term & $2.7305 \pm 0.52709$ & $47.9300 \pm 1.84913$ & $34.0800 \pm 1.10718$ \\
Preterm & $2.1609 \pm 0.38976$ & $47.4541 \pm 1.81987$ & $33.8180 \pm 0.98478$ \\
\hline Chettri:
\end{tabular}


Antropometric Measurements in Different Ethnic groups of Nepalese New Borns

\begin{tabular}{|c|c|c|c|}
\hline \multicolumn{4}{|l|}{ Magar: } \\
\hline Term & $2.8870 \pm 0.65738$ & $48.4900 \pm 1.61117$ & $33.7900 \pm 1.52617$ \\
\hline Preterm & $2.3875 \pm 0.8798$ & $47.9000 \pm 1.56689$ & $33.5500 \pm 1.46876$ \\
\hline \multicolumn{4}{|l|}{ Newar: } \\
\hline Term & $2.8000 \pm .56707$ & $48.3300 \pm 1.37109$ & $34.5100 \pm 1.30651$ \\
\hline Preterm & $2.3260 \pm 0.48065$ & $47.6956 \pm 1.2887$ & $34.0998 \pm 1.27651$ \\
\hline \multicolumn{4}{|l|}{ Total: } \\
\hline Term & $2.8177 \pm 0.61149$ & $47.6800 \pm 2.48083$ & $33.5650 \pm 2.02961$ \\
\hline Preterm & $2.2153 \pm 0.41075$ & $46.3600 \pm 2.39100$ & $32.2310 \pm 0.03891$ \\
\hline
\end{tabular}

Table 3: Comparison of Anthropometric measurements in different Ethnic groups

\begin{tabular}{|c|c|c|c|c|c|c|c|}
\hline & $\mathbf{t}$ & Df & $p$ value & & $\mathbf{t}$ & df & $p$ value \\
\hline \multicolumn{8}{|c|}{ Brahmin vs Gurung } \\
\hline Weight & -8.647 & 198 & 0.000 & $\begin{array}{c}\text { Gurung vs Newar } \\
\text { Weight }\end{array}$ & 6.149 & 198 & 0.000 \\
\hline Length & -10.266 & 198 & 0.000 & Length & 5.173 & 198 & 0.000 \\
\hline OFC & -5.374 & 198 & 0.000 & OFC & 1.363 & 198 & 0.000 \\
\hline \multicolumn{8}{|c|}{ Brahmin vs Dalit } \\
\hline Weight & -.420 & 198 & 0.675 & $\begin{array}{c}\text { Dalit vs Chettri } \\
\text { Weight }\end{array}$ & .171 & 198 & 0.864 \\
\hline Length & -2.419 & 198 & 0.016 & Length & -1.279 & 198 & 0.203 \\
\hline OFC & 8.378 & 198 & 0.000 & OFC & -13.519 & 198 & 0.000 \\
\hline \multicolumn{8}{|c|}{ Brahmin vs Chettri } \\
\hline Weight & -1.906 & 198 & 0.058 & $\begin{array}{l}\text { Dalit vs Magar } \\
\text { Weight }\end{array}$ & -1.289 & 198 & 0.199 \\
\hline Length & -6.188 & 198 & 0.000 & Length & -1.279 & 198 & 0.203 \\
\hline OFC & -2.628 & 198 & 0.009 & OFC & -9.522 & 198 & 0.000 \\
\hline \multicolumn{8}{|c|}{ Brahmin vs Magar } \\
\hline Weight & -3.472 & 198 & 0.001 & $\begin{array}{c}\text { Dalit vs Newar } \\
\text { Weight }\end{array}$ & .186 & 198 & 0.754 \\
\hline Length & -7.817 & 198 & 0.000 & Length & -1.396 & 198 & 0.138 \\
\hline OFC & -1.378 & 198 & 0.170 & OFC & -10.446 & 198 & 0.000 \\
\hline \multicolumn{8}{|c|}{ Brahamin vs Newar } \\
\hline Weight & -2.688 & 198 & 0.008 & $\begin{array}{c}\text { Chettri vs Magar } \\
\text { Weight }\end{array}$ & -1.461 & 198 & 0.146 \\
\hline Length & -7.587 & 198 & 0.000 & Length & .000 & 198 & 1.000 \\
\hline OFC & -4.163 & 198 & 0.000 & OFC & 2.443 & 198 & 0.015 \\
\hline \multicolumn{8}{|c|}{ Gurung vs Dalit } \\
\hline Weight & -.469 & 198 & 0.640 & $\begin{array}{c}\text { Chettri vs, Newar } \\
\text { Weight }\end{array}$ & -.898 & 198 & 0.370 \\
\hline Length & 3.590 & 198 & 0.000 & Length & -1.738 & 198 & 0.084 \\
\hline OFC & 17.910 & 198 & 0.000 & OFC & -2.511 & 198 & 0.013 \\
\hline \multicolumn{8}{|c|}{ Gurung vs Chettri } \\
\hline Weight & -.315 & 198 & 0.753 & $\begin{array}{c}\text { Magar Vs Newar } \\
\text { Weight }\end{array}$ & 1.002 & 198 & 0.318 \\
\hline Length & 2.809 & 198 & 0.005 & Length & .756 & 198 & 0.450 \\
\hline OFC & 4.820 & 198 & 0.000 & OFC & -3.584 & 198 & 0.000 \\
\hline \multicolumn{8}{|c|}{ Gurung vs Magar } \\
\hline Weight & -1.643 & 198 & 0.102 & & & & \\
\hline Length & 2.809 & 198 & 0.005 & & & & \\
\hline OFC & 6.482 & 198 & 0.000 & & & & \\
\hline
\end{tabular}


Table 4: Correlation of weight, length and OFC with gestation age

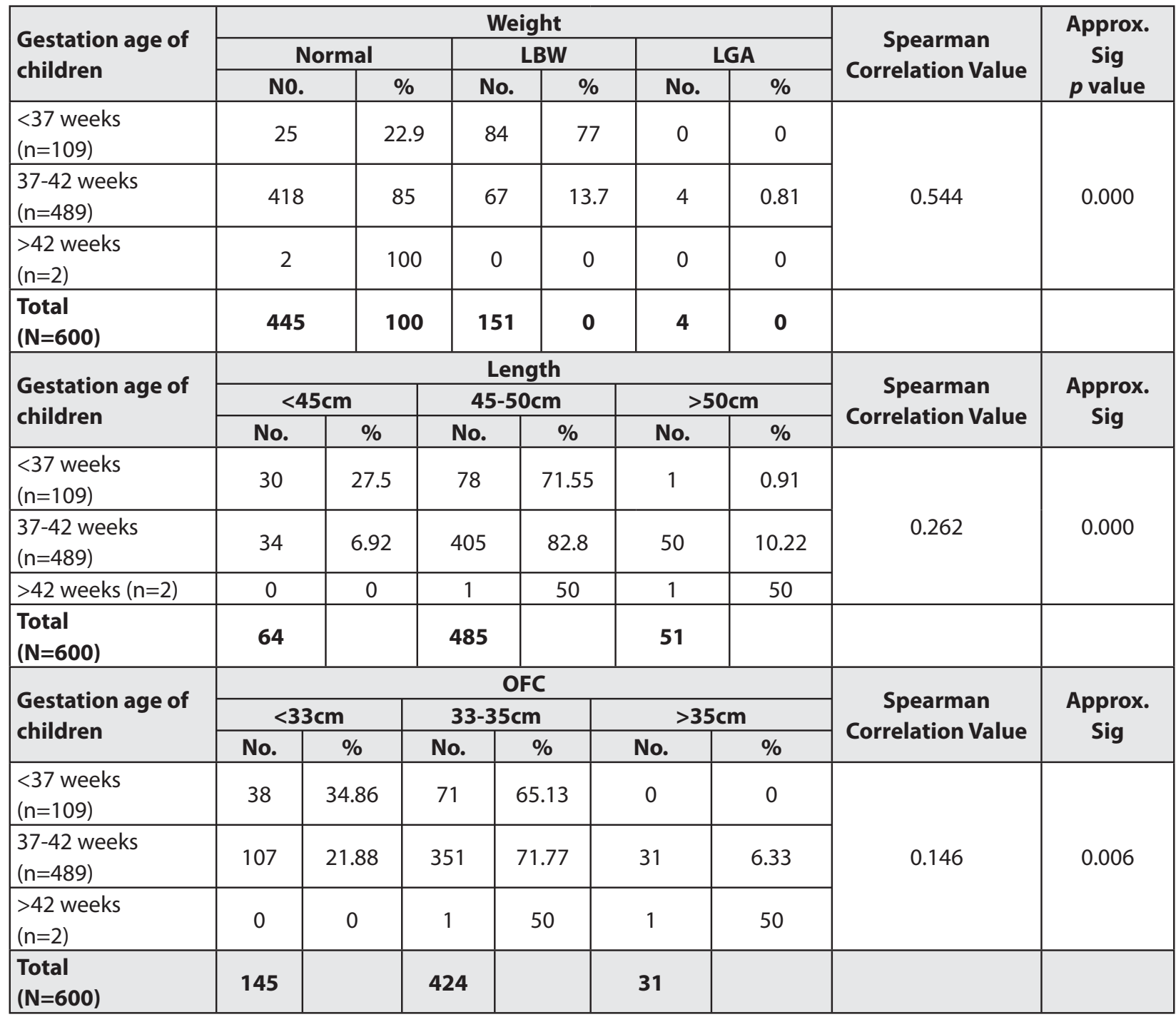

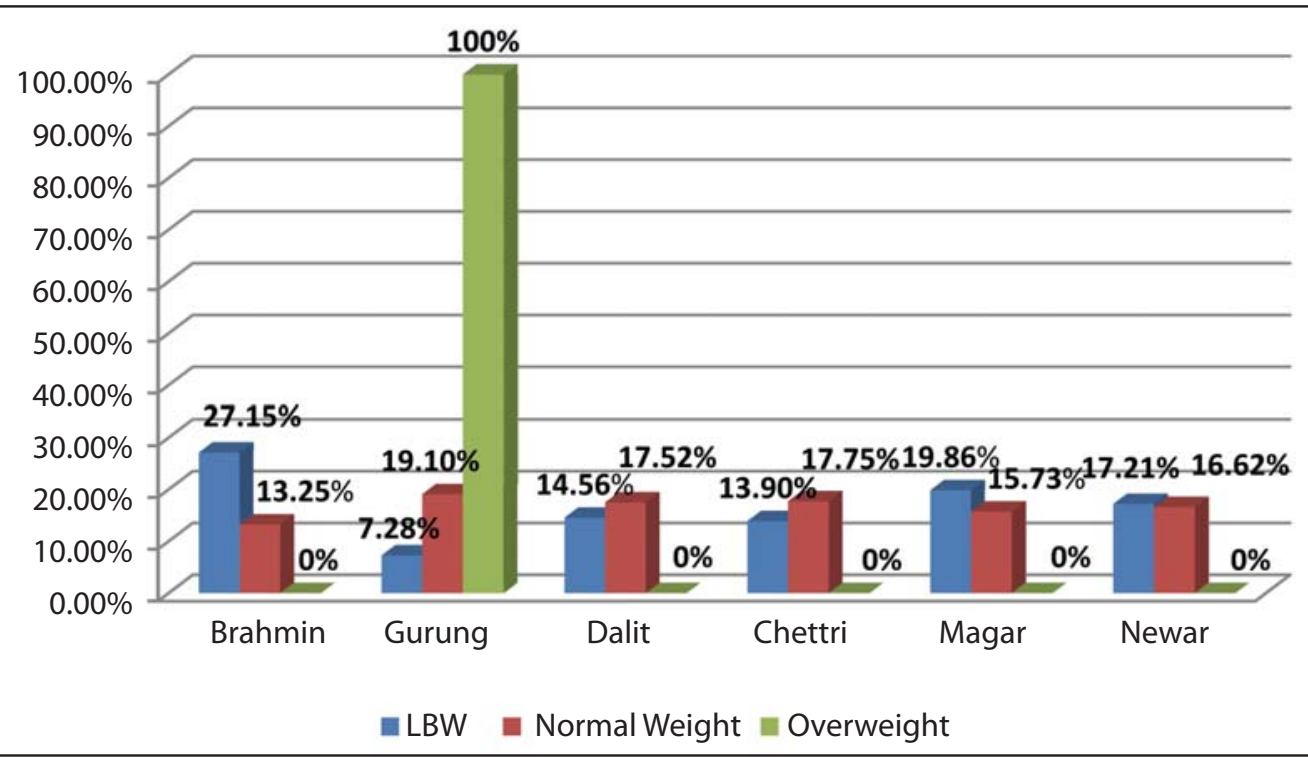

Fig 3: Distribution of weight in different Ethnic Groups

*** LBW (<2500gms, $n=151$ ) 25\%, **Normal weight (2500gms-3.999gms, $n=445) 74.16 \%$,

* Overweight (>4000gm, $\mathrm{n}=4)$ 0.66\% 


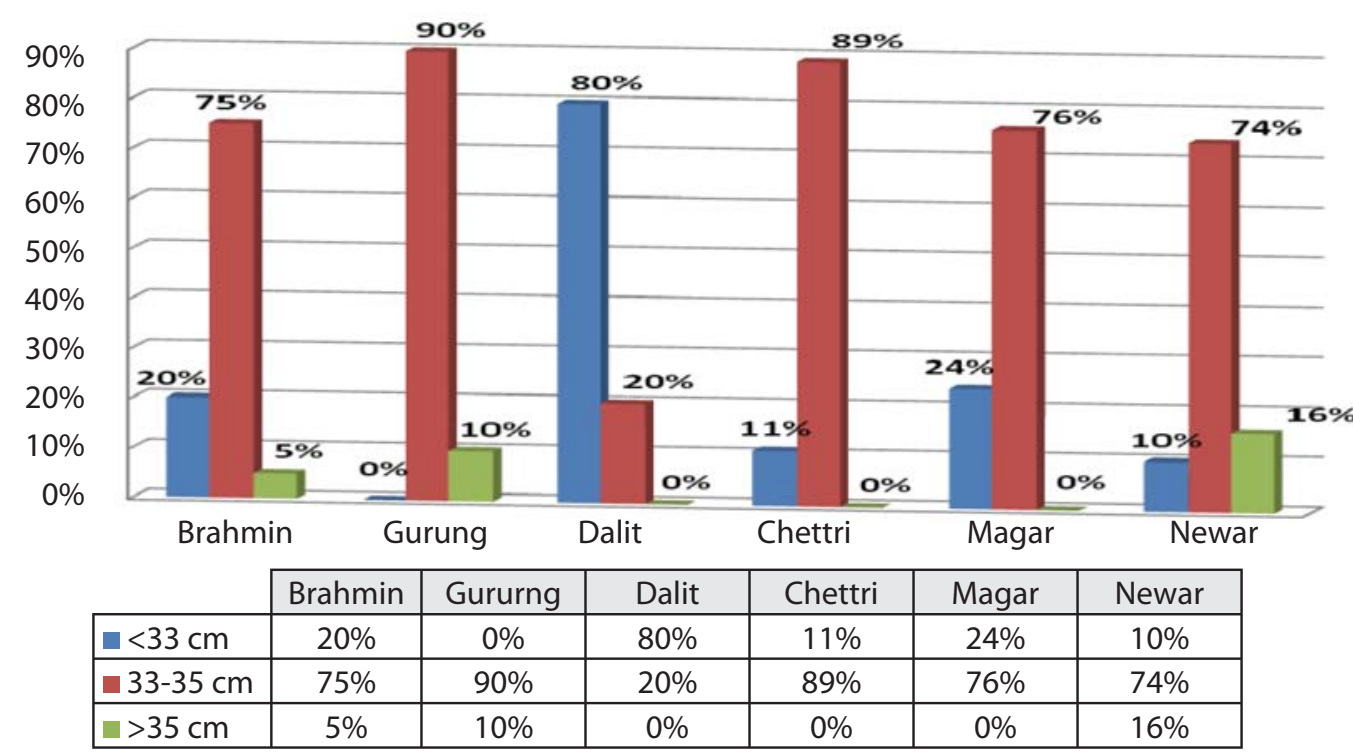

Fig 4: OFC in different Ethnic Groups

\section{Discussion}

The term anthropometric refers to comparative measurements of the body and is important indicator of child survival. The periodic measurement of anthropometric variables in different populations and regions of a country reflect changes in nutrition and health status of the country and is a reliable tool to evaluate social health ${ }^{2,3}$. the anthropometric measurements commonly used as indices of growth include length, weight, and head circumference. These measurements utilized at present time are based on the results obtained for more than five decades, which are not able to determine a national pattern most likely due to some ethnic influences ${ }^{4}$ In addition Genetic differences exist among races regarding growth and body composition ${ }^{3}$. Some investigators have also argued for ethnic-specific standards ${ }^{5,6}$. Although the World Health Organization (WHO) advises a single international growth standard for developing countries ${ }^{7,8}$, the ideal is to establish local national growth charts reflecting each country's own genetic characteristics. Hence this analytical descriptive study was carried out to observe the differences in these parameters in different gestation age and ethnic groups.

In this study, out of 600 newborns there were 326 (54\%) males and 274 (46\%) females. Brahmin, Gurung, Dalit, Chettri, Magar and Newar were the 6 major ethnic groups attending this hospital for delivery. There were $124(20.66 \%)$ SGA birth weight $<10^{\text {th }}$ percentile for gestational age\}, 109 (18.16\%) preterms \{born at $<37$ completed weeks\}, 463(77.16\%). Appropriate for age (AGA) and $13(2.16 \%)$ Large for gestation age (LGAweight 90th percentile for gestational age) babiesusing the reference ranges provided by Alexander et al $^{9}$.
Our finding was different from another study ${ }^{10}$ where prematurity was observed in $25.5 \%$ and SGA in $14.1 \%$ of the neonates. The reason for this may be that the adverse intrauterine environment and other risk factors vary in different countries.

Highest number of SGA (27.41\%) and preterms (33.02\%) were seen in Brahmin compared to other Ethnic Groups. Whereas highest number of large for date babies (LGA) 9/13 was seen in Gurung population. Number of preterms was higher than SGA in Brahmin, Newar and Magar and SGA was higher than Preterms in Dalit, Gurung, Chettri populations. Prematurity and SGA prevalence reflects an adverse intrauterine environment; hence comparisons of risk factors at birth like primiparous vs multiparous mothers, smoker's vs nonsmokers, twin's vs singletons, in detail should be considered which was not seen in this study. If these factors were considered maybe we could explain why in some ethnic groups SGA was common and preterm in others. The observed Mean \pm SD of weight, length and OFC for term babies were $2.8177 \pm 0.61 \mathrm{gms}$, $47.68 \pm 2.48 \mathrm{~cm}, 33.56 \pm 2.02 \mathrm{~cm}$ respectively and for preterm babies it was $2.2153 \pm 0.41075 \mathrm{gms}, 46.36 \pm 2.39$ $\mathrm{cm}, 32.23 \pm 2.03 \mathrm{~cm}$ respectively. The findings of term babies were comparable to study conducted by Manandhar K, Manandhar DS et al ${ }^{11}$ in Kathmandu and $S$ Muthayya, P Dwarkanath et $\mathrm{al}^{12}$ in south India. This similarity could have been due to similar population and cultural backgrounds. In another study conducted by B. Telatar, S. Comert et $\mathrm{al}^{13}$ mean birth weight, height and head circumference was 3334 (SD 494) gm, 48.3 (SD 2.2) $\mathrm{cm}$ and 34.4 (SD 1.3) $\mathrm{cm}$ respectively which was greater than our study. Yet another study by Nahar et al $^{14}$ reported a birth weight of $2690 \mathrm{gm}(S D=0.36)$ which was 
lower than in our study. These two studies were carried out in Iceland and Bangladesh respectively and the differences in demographic factor, different population and cultural backgrounds again could have made a difference in the results. A study by Hickey states that sociocultural dimensions, ethnicity, social support etc can also affect the gestational weight gain ${ }^{15}$.

The mean weight of preterm babies was much less $(1780 \mathrm{gm})$ in another study ${ }^{16}$ compared to ours (2.2153gms). The reason for this is that in our study gestation age $\leq 32$ weeks and weight $\leq 1500$ gms was not taken into consideration whereas all preterms was included in above mentioned study. For preterm comparable study was not available for length and OFC. These parameters when compared with different Ethnic groups showed that in Term newborns weight, length and OFC was noted to be highest in Gurungs $(3.3004 \mathrm{gms}, 49.35 \mathrm{~cm}, 34.72 \mathrm{~cm})$ and was statistically significant $(p<0.000)$.Weight and length of Brahmins was lowest $(2.578 \mathrm{gms}, 45.49 \mathrm{~cm})$ and OFC was lowest in Dalits $(30.88 \mathrm{~cm}$, statistically significant $<0.000)$. In case of preterms highest weight and length was seen in Magars $(2.387 \mathrm{gms}, 47.90 \mathrm{~cm})$ but OFC was highest in Gurungs $(34.18 \mathrm{~cm})$ whereas weight was lowest in chettri (2.1609gms), length in Brahmin $(44.61 \mathrm{~cm})$ and OFC in Dalits $(29.92 \mathrm{~cm})$. The difference between the different Ethnic groups could be due to varying, socioeconomic, nutritional and environmental factors of the underlying population as already mentioned earlier. Factors other than ethnicity include altitude, maternal size, parity, smoking, parental social position which can affect fetal growth and could confound the ethnic differences which has been observed in numerous other studies $5,6,17,18$. These factors were also present in our study but was not analyzed in detail.

WHO defines Low Birth Weight (LBW) as birth weight less than $2500 \mathrm{gms}$. The definition of LBW does not take into account the gestation period.LBW observed in our study was $25 \%$ which is lower than that observed in another study which was $37.75 \%{ }^{10}$. Even within the country $29.8 \%$ and $28.6 \%$ LBW was noted in two other studies carried out in western region hospital, Pokhara in 2004 (7 years ago) ${ }^{19}$ and Sarlahi in 2007(5years ago) ${ }^{20 .}$ The first study was done in same city Pokhara but it is observed that in present study the rate of LBW has decreased. The probable cause for this difference may be the low educational and socioeconomic status of the mothers in the previous study. As western region hospital is a government hospital, so mothers attending that hospital are probably from lower socioeconomic group. Lower birth weight in this study indicates the poor socioeconomic status of the mothers. Decrease in LBW cases in 7 years time may also indicate improvement in health status of the country, awareness in people regarding antenatal care. Yet in another study ${ }^{21}$ carried out in same city pokhara 3 years ago (2008) out of 400 newborns only $8.5 \%$ was found to be LBW, which is much lower than our findings. This difference may be due to the fact that their study included only term babies whereas our study has included term as well as preterm babies.

Highest number of Low birth babies (LBW) were found in Brahmins (27.15\%) followed by Magar (19.86\%), Newar (17.21\%), Dalit (14.56\%), Chettri (13.90\%). Only $7.28 \%$ LBW was seen in Gurung population. The reason for the Gurungs to be heavier, longer, and with larger heads than other groups may be due to the fact that genetically they are of heavy built and has a good nutrition status. A data analysis done in $2004^{19}$ where the group was divided as Indo-Aryan (Brahmin, Chettris of our group) and lower caste (Dalit of our group) ethnic groups had significantly lower weight babies than Tibeto-Burman (Gurung, Magar of our group) and Newar groups. This was consistent with our study. Like their findings Brahmin and Dalit had lower weight than other Ethnic groups. Again they found that Tibeto Burman group and Newars had higher birth weight, this was again similar with our study. This similarity in the findings may support our finding in establishing ethnic specific standard.

Other two parameters of length and head circumference in different Ethnic groups were also compared in our study. A comparable study for this in different Ethnic groups of the country was not available. Hence we can state that possibly this is the first study of this kind, so it is not possible to conclude anything for these parameters. However irrespective of any ethnic groups the mean length and OFC of Nepalese newborns noted by Manandhar K, Manandhar DS et al $^{11}$ was $49 \mathrm{~cm}$ and $33.8 \mathrm{~cm}$ respectively and mean OFC noted by Sreeramareddy CT, Chuni N, Patil R, Singh D, Shakya $B^{21}$ was $33.5 \mathrm{~cm}$ which was comparable to our study. Correlation of gestation age with weight, length and OFC was also seen and these parameters were directly proportion to gestation age and was statistically significant $(p<0.000)$. Similar correlation was also observed in another study ${ }^{22}$.

\section{Conclusion}

Periodical updating of anthropometric variables in different populations in a country is necessary to reflect ongoing changes in local conditions. The limitation of this study is that the anthropometric values obtained reflect the results of only one hospital and a limited population; hence generalization to the whole Nepalese Population cannot be made. Furthermore our study is populationbased, rather than hospital-based, which makes the selection biased. Other factors which could affect fetal 
growth were not analyzed. Despite these limitations, we believe that our results could provide a useful analytic comparison tool for future research. Therefore we would reccomend parallel studies to be made in various regions of the country comprising multiple socio-economic, nutritional, cultural backgrounds, so that comparative analyses could be made with newfound results. The practical application of ethnic-specific standards requires further research in a larger scale.

\section{Acknowledgements: None \\ Funding: None \\ Conflict of Interest: None \\ Permission from IRB: Yes}

\section{References}

1. Ballard JL, Khoury JC, Wedig K, et al: New Ballard Score expanded to include extremely premature infants. J Pediatr 1991;119:417-23.

2. Tanner JM. Growth as a mirror of the condition of society: secular trends and Class distinctions. Acta Pediatric Japonica 1987;29:96-103.

3. Neyzi O, Saka HN. Anthropometric studies in Turkish children. Istanbul Med Faculty J 2002;65: 221-8.

4. K. Kalra, N. Kishore, R. S. Dayal: Anthropometric measurements in the newborn. Indian J Pediatr 1967:34:73-82.

5. Davies DP, Senior N, Cole G, Blass D, Simpson K: Size at birth of Asian and white Caucasian babies born in Leicester: implications for obstetric and pediatric practices. Early Hum Dev 1982;6:257-63.

6. Wang X, Guyer B, Paige DM: Differences in gestational age-specific birth weight among Chinese, Japanese and White Americans. Int J Epidemiol 1994;23:119-28.

7. Ulijaszek SJ. Between population variation in pr-adolescent growth. European J Clin Nutrition 1994;48:5-13.

8. A growth chart for international use in maternal and child health care: guidelines for primary health care personnel. Geneva, World Health Organization, 1978.

9. Alexander GR, Himes JH, Kaufman RB, Mor J, Kogan M. A United States national reference for fetal growth. Obstet Gynecol 1996;87:163-8

10. Gozal D, Ndombo PK, Ze Minkande J, Kago I, Tetanye E, Mbede J.Anthropometric measurements in a newborn population in west Africa: a reliable and simple tool for the identification of infants at risk for early postnatal morbidity. J Pediatr 1991;118(5):800-5.

11. Manandhar K1, Manandhar DS2, Baral MR3One year follow up study of term babies born at Kathmandu medical college teaching hospital. Kathmandu Univ Med J. 2004;2(4):286-90.

12. S Muthayya, $P$ Dwarkanath, $T$ Thomas, M Vaz, A Mhaskar, R Mhaskar, A Thomas, S Bhat and AV Kurpad. Anthropometry and body composition of south Indian babies at birth. Public Health Nutr 2006;9:896-903

13. B. Telatar, S. Comert, A. Vitrinel and E. Erginöz. Anthropometric measurements of term neonates from a state hospital in Turkey. Eastern Mediterranean Health J 2009;15(6)1412-419.

14. Nahar S, Mascie-Taylor CGN, Begum HA. Maternal anthropometry as a predictor of birth weight. Public Health Nutr 2006;10:965-70.

15. Hickey CA. Sociocultural and behavioral influences on weight gain during pregnancy. Amer J Clin Nutr 2000;71:1364-70.

16. Jaya DS, Kumar NS, Bai LS.Anthropometric indices, cord length and placental weight in newborns. Indian Pediatr 1995;32(11):1183-8.

17. Singh GK, Yu SM: Birthweight differentials among Asian Americans. Am J Public Health 1994;84:144449.

18. Munroe $M$, Shah $C P$, Badgley $R$, Bain HW: Birth weight, length, head circumference and bilirubin level in Indian newborns in the Sioux Lookout Zone, northwestern Ontario. Can Med Assoc J. 1984;131:453-56

19. Pratima Poudel Acharya; Fiona Alpass Birth Outcomes Across Ethnic Groups Of Women in Nepal. Health Care for Women International 2004; 25(1)40-54.

20. L C Mullany; G L Darmstadt; S K Khatry; S C Leclerq; J M Tielsch Relationship between the surrogate anthropometric measures, foot length and chest circumference and birth weight among newborns of Sarlahi, Nepal. Eur J Clin Nutr 2007;61:40-6.

21. Sreeramareddy CT, Chuni N, Patil R, Singh D, Shakya B.Anthropometric surrogates to identify low birth weight Nepalese newborns: a hospital-based study. BMC Pediatr 2008;25;8:16.

22. B. F. Kalanda, S. Van Buuren, F. H. Verhoeff, B. J. Brabin. Anthropometry of Malawian live births between 35 and 41 weeks of gestation: Annals Human Biol 2005;32(5):639-49.

\section{How to cite this article?}

Malla K, Mall T, Rao S, Gauchan E, Basnet S, Koirala DP. Antropometric Measurements in Different Ethnic groups of Nepalese New Borns. J Nepal Paediatr Soc 2012;32(1):1-8. 